\title{
Possible control of paternal imprinting of polymorphisms of the ADAM33 gene by epigenetic mechanisms and association with level of airway hyperresponsiveness in asthmatic children
}

\author{
Frantisek Kopriva ${ }^{a}$, Marek Godava ${ }^{b}$, Marie Markovab ${ }^{b}$ Radek Vodicka ${ }^{b}$, Ladislav Dusekc, Jiri Muzikc, Eva Schneiderovab \\ Radek Vrtel ${ }^{\mathrm{b}}$, Vladimir Mihal ${ }^{\mathrm{a}}$
}

\begin{abstract}
Introduction. ADAM33 is the candidate gene most commonly associated with asthma and airway hyperreactivity (AHR). Aim. The aim of this study was to determine whether level of AHR is associated with certain alleles or haplotypes of the ADAM33 gene in asthmatic children.

Methods. One hundred and nine asthmatic children and 46 controls from the general population were examined with spirometry before and after histamine and methacholine inhalation. All subjects were genotyped for single-nucleotide polymorphisms (SNPs) of the ADAM33 gene. Haplotypes were determined according to genotypes of the patient's parents.

Results. We found the three most frequent ADAM33 haplotypes (a1-3) were associated with the highest level of AHR to methacholine and histamine in $66 \%$ of asthmatic children. The paternally transmitted GGGCTTTCGCA haplotype was seen in $73.3 \%$ asthmatic children with serious AHR to methacholine challenge (paternal and maternal origin of haplotype $73.3 \%$ to $37.5, P=0.046$ ) Significant differences in the relative frequency of paternal haplotypes with high levels of AHR to histamine were found $(P=0.013)$.

Conclusion. ADAM33 haplotypes $(\mathrm{a} 1, \mathrm{a} 2, \mathrm{a} 3)$ are associated with severity of AHR and are significantly more often transmitted in the paternal line.
\end{abstract}

Key words: bronchial asthma, bronchial hyperresponsiveness, ADAM33, paternal haplotypes

Received: August 31, 2012; Accepted: March 27, 2013; Available online: April 23, 2013

http://dx.doi.org/10.5507/bp.2013.025

${ }^{a}$ Department of Paediatrics, University Hospital Olomouc and Faculty of Medicine and Dentistry, Palacky University Olomouc, Czech Republic

${ }^{b}$ Department of Medical Genetics and Fetal Medicine, University Hospital Olomouc and Faculty of Medicine and Dentistry, Palacky University Olomouc

'Institute of Biostatistics and Analyses, Masaryk University Brno

Corresponding author: Frantisek Kopriva, e-mail:Koprivaf@fnol.cz

\section{INTRODUCTION}

Asthma is heterogeneous disorder of the airways, with intermittent airflow obstruction frequently accompanied by increased responsiveness of the bronchi to a wide variety of exogenous and endogenous stimuli. The main pathogenic mechanism of asthma is thought to be of chronic eosinophil-based inflammation of the bronchial mucosa. Airway hyperresponsiveness (AHR) is one of the key features of asthma and is known to directly correlate with the severity of asthmatic symptoms ${ }^{1}$.

Complex interactions between environmental and genetic factors give rise to the clinical appearance of asthma. In the last decade, candidate genes responsible for asthma development have been identified. ADAM33 (a disintegrin and metallopeptidase domain 33) is one of genes identified in a locus on the short arm of chromosome 20 that has been linked to asthma and bronchial hyperresponsiveness (Ref Shapiro NEJM 2002)2. ADAM33 belongs to a subgroup of metalloproteinases and is expressed by lung fibroblasts and bronchial smooth-muscle cells ${ }^{1}$. Several polymorphisms of ADAM33 gene have been studied. Several single-nucleotide polymorphisms (SNPs) are associated with asthma in some studies but others are not linked to the disease ${ }^{3-6}$. Since each of the SNPs probably contributes to the overall manifestation of asthma, haplotype association studies may be more revealing (ref Ederwegh and Howard). Distinct asthma susceptibility genomic loci have also been mapped to chromosomal region $12 \mathrm{q} 13-24$. This region is linked to bronchial asthma and to associated phenotypes, such as elevated IgE levels ${ }^{7-9}$.

AHR is usually defined as increased sensitivity of the airways to a variety of nonsensitizing agents that act via different specific mechanisms ${ }^{3,4}$. It may reflect a common physiological pathway of several mechanisms leading to a lowered threshold of airway narrowing to bronchoconstrictive stimuli. Measurement of bronchial hyperreactivity provides quantitative insights into variable airflow obstruction. Histamine and methacholine act directly on the airway smooth muscle. Methacholine is an acetylcholine analogue that lacks the nicotinic action of acetylcholine. The sensitivity of the airways to these agents is commonly expressed as a provocative concentration/dose 
causing a $20 \%$ fall (PC/D20) in forced expiratory volume in $1 \mathrm{~s}$ (FEV1). When exposed to high concentrations of inhaled histamine or methacholine, asthmatic patients show excessive narrowing of the airway, as reflected by an elevated or absent maximal response plateau ${ }^{10-12}$.

Environmental influences and epigenetic mechanisms could pose important modifying factors shaping the asthma phenotype at the clinical level. General mechanisms of gene expression regulation are methylation and histone acetylation. Increase in histone acetyltransferase activity with decrease in histone deacetylase have been observed in asthma $^{13}$.

The aim of this study was to find whether ADAM33 SNPs are associated with asthma and the results of histamine and methacholine bronchoprovocation tests as assessed by dosimetry. We performed genotyping of some previously reported polymorphisms and examined the possible association of these polymorphisms and their haplotypes with asthma in families with asthmatic children.

\section{PATIENTS AND METHODS}

Our study was performed on a population of 109 children with asthma and their relatives (parents and siblings). Overall 375 persons in 108 families and 46 samples from the general population were studied.

The diagnosis of persistent mild atopic bronchial asthma (a positive skin prick test) was established, using the GINA 2002 guidelines, in 109 children (76 boys and 33 girls) aged 0.42 -20.20 years (median, 10.82 years) who were referred to the Allergy Clinic of the Department of Pediatrics from 2003 to 2005.

In all patients, the existence of atopy was evaluated by a skin prick test using common allergen extracts (grass and tree pollen, house dust mite, molds, cat dog extracts) and reactions $3 \mathrm{~mm}$ were regarded as positive (fy Stallergen).

Spirometry was performed in children prior to initiation of anti-inflammatory therapy. All subjects used antihistamines for a week prior to the testing. Salbutamol was not allowed in the morning before assessment. At the time of the study, all subjects had been free of any acute respiratory tract infection for 4 weeks. Subjects with baseline FEV1 $<80 \%$ of the predicted value were excluded.

Children with congenital airway anomalies or severe respiratory tract disease (e.g., cystic fibrosis) were excluded from the study. The study was approved by the Hospital Ethics Committee, and the parents of all children gave informed consent.

\section{Spirometry}

We used the Jaeger MasterScreen Spirometry system (Jaeger Co., Germany). Pulmonary function tests were performed in the sitting position. Baseline value at screening of FEV1, obtained from analysis of three consecutive efforts, was $\geq 80 \%$ of predicted, with $<5 \%$ variability. Each data point was the best of at lest three reproducible measurements (variability $<5 \%$ ). The result of pulmonary function test indices were expressed as absolute values and percentage of predicted values. The predicted values for each subject based on gender, age, weight and height were obtained from standard computerized formulas (ECCS 1993, Zapletal 1987 for children) (ref. ${ }^{14}$ ).

The histamine and methacholine solutions were prepared in different concentrations in buffered saline $(\mathrm{pH}$ 7.4) (Tables 1, 2). Each patient inhaled prepared histamine or methacholine solutions in increasing concentrations. The test was stopped when the fall in FEV1 was $\geq 20 \%$ compared to baseline.

\section{Genotyping and haplotyping}

DNA isolation from samples of whole peripheral blood was performed by standard salting out method. Genotypes in patients, their relatives and controls were identified using the allele discrimination/SNP's real time PCR. The probes for discrimination/SNP's real time PCR were obtained from the Applied Biosystem database of TaqMan ${ }^{\circledR}$ SNP genotyping assays or were alternatively designed by the manufacturer according to ours specifications. The PCR reaction was carried out in overall volume of $11 \mu \mathrm{L}$ with these components: $6.28 \mu \mathrm{L} \mathrm{H} \mathrm{H}_{2} \mathrm{O}, 0.02 \mu \mathrm{L}$ reference dye Rox 50x (Finnzymes), $4.0 \mu \mathrm{L}$ DyNamo $^{\mathrm{TM}}$

Table l. Protocol for histamine in dosimetric application.

\begin{tabular}{lllllll}
\hline \multicolumn{1}{c}{ Histamine } \\
\hline Levels $(\mathrm{mg} / \mathrm{mL})$ & 0.01 & 0.1 & 0.3 & 0.6 & 1.0 & 2.0 \\
Single dose $(\mathrm{mg})$ & 0.004 & 0.028 & 0.101 & 0.202 & 0.672 & 1.334 \\
Cumulated dose $(\mathrm{mg})$ & 0.004 & 0.032 & 0.133 & 0.335 & 1.370 & 2.714 \\
\hline
\end{tabular}

Table 2. Protocol for metacholine in dosimetric application.

\begin{tabular}{llllllc}
\hline & \multicolumn{1}{c}{ Methacholine } \\
\hline Levels $(\mathrm{mg} / \mathrm{mL})$ & 2.0 & 4.0 & 4.0 & 8.0 & 8.0 & 16.0 \\
Single dose $(\mathrm{mg})$ & 0.05 & 0.1 & 0.3 & 0.6 & 1.0 & 1.5 \\
Cumulated dose $(\mathrm{mg})$ & 0.05 & 0.15 & 0.45 & 1.05 & 2.05 & 3.55 \\
\hline
\end{tabular}


Probe qPCR Kit F-450S/L (Finnzymes), 0.2 $\mu \mathrm{L}$ SNP genotyping assay (Applied Biosystem) and $0.5 \mu \mathrm{L}$ DNA $(100 \mathrm{ng} / \mu \mathrm{L})$. Allele discrimination PCR was run on Stratagene MxPro3005 thermal cycler under the following conditions: starting denaturation at $95^{\circ} \mathrm{C}$ for $15 \mathrm{~min}$ and then 55 cycles including denaturation at $95^{\circ} \mathrm{C}$ for $15 \mathrm{~s}$ followed by annealing/denaturising step at $60{ }^{\circ} \mathrm{C}$ for $1 \mathrm{~min}$. The fluorescence $\mathrm{c}_{\mathrm{T}}$ values of probe, the gross and shape of curves from fluorescence readings were used to determine genotypes.

Observed genotypes were confirmed by direct sequencing of the SNPs of interest in 15 patients and their relatives, overall totalling 50 persons from 15 families. The sequencing reaction was carried out in a volume of $10 \mu \mathrm{L}$ with reagents obtained from Applied Biosystems. The reaction mixture contained: $2 \mu \mathrm{L}$ of primer, $2 \mu \mathrm{L}$ of PCR water (Top-Bio), $2 \mu \mathrm{L}$ of purified PCR amplicons and $4 \mu \mathrm{L}$ of ABI PRISM ${ }^{\circledR}$ Big Dye ${ }^{\circledR}$ Terminator $\mathrm{v} 3.1$ (4-times diluted by $5 \mathrm{x}$ sequencing buffer). The sequence reaction ran under the following thermal conditions: denaturation at $94{ }^{\circ} \mathrm{C}$ for $2 \mathrm{~min}$ and 34 cycles of $96{ }^{\circ} \mathrm{C}$ for $10 \mathrm{~s}$, with gradual $1{ }^{\circ} \mathrm{C}$ per $1 \mathrm{~s}$ temperature decreasing to $50{ }^{\circ} \mathrm{C}, 50{ }^{\circ} \mathrm{C}$ for $5 \mathrm{~s}$ and $60{ }^{\circ} \mathrm{C}$ for $4 \mathrm{~min}$. Products of sequencing reaction were purified ethanol precipitation) and capillary electrophoresis of the purified products was performed on an ABI PRISM ${ }^{\mathrm{TM}} 310$ Genetic Analyzer (Applied Biosystems).

Haplotypes were determined according to genotypes of the patient's parents. Nonconclusive haplotypes were inferred by using expectation maximization algorithm modified by partition ligation mode 41 and also using Bayes'theorem 42.

\section{Statistics}

Standard non-parametric statistics were used to describe primary data, i.e. absolute and relative frequencies, median and $10^{\text {th }}-90^{\text {th }}$ percentile range. Decrease in FEV $\geq 20 \%$ following histamine and methacholine inhalations were binary coded and analyzed statistically as a categorical variable. ML- $\chi^{2}$ test. Fisher's exact test was applied to assess associations among variants in categorical variables. When needed, standard Bonferroni correction was used for multiple comparisons. Corrections were done separately for SNPs and for haplotypes ${ }^{15-18}$.

\section{RESULTS}

109 children ( 76 boys and 33 girls) were included in the study, they were all assessed between 2003 and 2005 and given a diagnosis of moderate, persistent bronchial asthma according to GINA 2002. Genotypes (and allele frequencies) for the studied ADAM33 SNPs were successfully determined in all of the patients (109 asthmatic), relatives (parents and siblings) and 46 controls from the general population. We found some differences in allele frequencies of the studied SNPs between patients and control groups but these did not reach statistical significance (Table 3 ).

Based on the knowledge of parental genotypes in ADAM33 SNPs, we constructed haplotypes in patients (built from rs511898, rs2280092, rs3918396, rs528557, rs2853209, rs44707, rs2280091, rs2280089, rs628977, rs2787094, rs3746631 SNPs, respectively) (Table 4). The haplotypes were successfully determined in $64 \%$ for ADAM33 in patients and in $23.9 \%$ in the control group. We found three haplotypes were most common and we denoted them as a1-a3 for ADAM33 in descending order

Table 3. Frequencies of ADAM33 SNPs. The first one nucleotide each of SNP represents major allele, and then homozygote 1 is homozygote for major allele.

\begin{tabular}{|c|c|c|c|c|c|c|}
\hline $\begin{array}{l}\text { SNP/ } \\
\text { Genotypes }\end{array}$ & $\begin{array}{c}\text { IN2-SNP2 } \\
-\mathrm{G} / \mathrm{A} \\
\text { rs324012 } \\
\end{array}$ & $\begin{array}{c}\text { IN2-SNP3 } \\
-\mathrm{C} / \mathrm{T} \\
\text { rs324011 } \\
\end{array}$ & $\begin{array}{c}\text { IN17 } \\
-\mathrm{T} / \mathrm{C} \\
\mathrm{rs} 841718 \\
\end{array}$ & $\begin{array}{c}\text { IN18 } \\
-\mathrm{C} / \mathrm{T} \\
\mathrm{rs} 3024974 \\
\end{array}$ & $\begin{array}{c}\text { 3UTR-SNP3 } \\
-\mathrm{A} / \mathrm{G} \\
\text { rs } 1059513\end{array}$ & $\begin{array}{c}\text { 3UTR-SNP4 } \\
\text { - A/G } \\
\text { rs4559 }\end{array}$ \\
\hline Homozygote 1 & 0.28 & 0.37 & 0.30 & 0.81 & 0.88 & 0.34 \\
\hline Heterozygote & 0.48 & 0.42 & 0.53 & 0.18 & 0.11 & 0.54 \\
\hline Homozygote 2 & 0.25 & 0.21 & 0.17 & 0.01 & 0.01 & 0.12 \\
\hline Alleles & $\mathbf{G}-\mathbf{A}$ & $\mathbf{C}-\mathbf{T}$ & $\mathbf{T}-\mathbf{C}$ & $\mathbf{C}-\mathbf{T}$ & $\mathbf{A}-\mathbf{G}$ & $\mathbf{A}-\mathbf{G}$ \\
\hline Major allele & 0.51 & 0.58 & 0.57 & 0.90 & 0.94 & 0.61 \\
\hline Minor allele & 0.49 & 0.42 & 0.43 & 0.10 & 0.06 & 0.39 \\
\hline \multicolumn{7}{|c|}{ Control group $(\mathrm{N}=45)$} \\
\hline $\begin{array}{l}\text { SNP/ } \\
\text { Genotypes }\end{array}$ & $\begin{array}{c}\text { IN2-SNP2 } \\
-\mathrm{G} / \mathrm{A} \\
\text { rs324012 }\end{array}$ & $\begin{array}{c}\text { IN2-SNP3 } \\
-\mathrm{C} / \mathrm{T} \\
\text { rs } 324011 \\
\end{array}$ & $\begin{array}{c}\text { IN17 } \\
-\mathrm{T} / \mathrm{C} \\
\mathrm{rs} 841718 \\
\end{array}$ & $\begin{array}{c}\mathrm{IN} 18 \\
-\mathrm{C} / \mathrm{T} \\
\mathrm{rs} 3024974\end{array}$ & $\begin{array}{c}\text { 3UTR-SNP3 } \\
-\mathrm{A} / \mathrm{G} \\
\text { rs } 1059513\end{array}$ & $\begin{array}{c}\text { 3UTR-SNP4 } \\
\text { - A/G } \\
\text { rs4559 }\end{array}$ \\
\hline Homozygote 1 & 0.31 & 0.31 & 0.42 & 0.89 & 0.89 & 0.44 \\
\hline Heterozygote & 0.53 & 0.56 & 0.47 & 0.11 & 0.11 & 0.51 \\
\hline Homozygote 2 & 0.16 & 0.13 & 0.11 & 0.00 & 0.00 & 0.04 \\
\hline Alleles & G-A & $\mathbf{C}-\mathbf{T}$ & $\mathbf{T}-\mathbf{C}$ & $\mathbf{C}-\mathbf{T}$ & $A-G$ & $A-G$ \\
\hline Major allele & 0.58 & 0.59 & 0.66 & 0.94 & 0.94 & 0.70 \\
\hline Minor allele & 0.42 & 0.41 & 0.34 & 0.06 & 0.06 & 0.30 \\
\hline
\end{tabular}


according to frequency. The frequency of the most common ADAM33 haplotypes was not significantly different for patients and controls (Table 5). We were unable to analyze minor haplotypes but their mild contribution (together as a group) to the final asthma phenotype cannot be ruled out.

One hundred and nine children started the histamine bronchoprovocation tests. All histamine and methacholine bronchoprovocation tests were completed by 99 children with a percentage decrease in FEV1 $20 \%$ to baseline FEV1. Cough and nausea developed as the percentage of FEV $1 \geq 20 \%$ decreased in $53(75 \%)$ children using histamine and in 41 (58\%) children using methacholine. Low level of AHR PC - $2 \mathrm{mg} / \mathrm{mL}$ histamine (Provocation concentration) and $-16 \mathrm{mg} / \mathrm{mL}$ methacholine was observed in $28(28 \%)$ of the asthmatic children (group I). Medium to high level of AHR PC $20 \leq 2 \mathrm{mg} / \mathrm{mL}$ histamine and PC20 $\leq 16 \mathrm{mg} / \mathrm{mL}$ methacholine was observed in $71(72 \%)$ of the asthmatic children (group II).

We investigated the association of ADAM33 haplotypes to level of AHR in histamine and methacholine bronchoprovocation tests in asthmatic patients. All three most common haplotypes (a1-3) were related to AHR in 47 asthmatic children (66\%).

Medium-high levels of AHR were linked significantly to a3 haplotype and moreover there was a difference in a3 haplotype distribution according to parental origin $73.3 \%$ of patients with positive bronchoprovation test after methacholine challenge shared a3 haplotype of paternal origin ( $P=0.046)$ vs. $37.5 \%$ of patients with maternal origin of the haplotype. We found statistically significant differences in relative frequency of paternal haplotypes with serious levels of AHR to histamine $(P=0.013)$ (Tables $6 \mathrm{a}, \mathrm{b})$.

The other ADAM33 haplotypes were also associated with AHR, although their linkage was not as significant as for a3, and hence the effect on AHR by themselves could not be distinguished.

\section{DISCUSSION}

In this study, we investigated the influence of 11 ADAM33 SNPs on asthma and the level of AHR in intron or untranslated regions (UTR) regions. We investi- gated ADAM33 SNPs in 109 children with asthma and 46 healthy controls. We found differences in SNPs distribution between asthmatics and controls but they were not significant. The group size was relatively small but sufficient for statistical significance, as seen in similar studies. ADAM33 was identified as an asthma susceptibility gene using a positional cloning approach in sib-pair populations from the United States and the United Kingdom. In four independent asthma populations (African American, US Caucasian, US Hispanic, and Dutch Caucasian) linkage to chromosome $6 \mathrm{p}$ was found only in the US Caucasian population. The lack of linkage in the other populations suggests that ADAM33 confers a modest effect but a fairly large attributable risk, as previously described for complex disease genes in which common alleles contribute to susceptibility ${ }^{4}$.

We compared allele and common haplotype (constructed from SNPs found in all relevant studies) from our study with published data from Caucasian populations ${ }^{19,20}$ and we found that the frequencies of SNPs were similar.

The studies used a software-based procedure (an expectation-maximisation algorithm) for haplotype structure identification and to determine whether the differences in

Table 4. Marking of polymorfisms of ADAM33.

\begin{tabular}{cc}
\hline “Conventional marking” & rs ID polymorfisms \\
\hline F+1 & rs511898 \\
L-1 & rs2280092 \\
S1 & rs3918396 \\
S2 & rs528557 \\
S+1 & rs2853209 \\
ST+4 & rs44707 \\
T1 & rs2280091 \\
T+1 & rs2280091 \\
V_3 & rs628977 \\
V4 & rs2787094 \\
V5 & rs3746631 \\
\hline
\end{tabular}

F+1 (rs511898), L-1 (rs2280092), S1 (rs3918396), S2 (rs528557), S+1 (rs2853209), ST+4 (rs44707), T1 (rs2280091), T+1 (rs2280089), V_3 (rs628977), V4 (rs2787094), V5 (rs3746631),

Table 5. Frequency of ADAM33 haplotypes. Legend shows alphanumerical code for haplotype denotation, 1 stands for major allele and 2 stands for minor allele of studied SNPs. The haplotypes are made from $\mathrm{F}+1, \mathrm{~L} \_1, \mathrm{~S} 1, \mathrm{~S} 2, \mathrm{~S}+1, \mathrm{ST}+4, \mathrm{~T} 1, \mathrm{~T}+1, \mathrm{~V} \_3$, V4 and V5 SNPs (respectively) in ADAM33.

\begin{tabular}{clcc}
\hline Haplotype & Haplotype & Patients [\%] & Controls [\%] \\
\hline a3 & GGGCTTTCGCA & 17.60 & 6.50 \\
a2 & GGGCACTCGCA & 14.40 & 5.40 \\
a1 & AAGGATCTGCA & 10.40 & 4.30 \\
& GGGCACTCGGA & 5.90 & 3.30 \\
& AGGCACTCGC & 4.10 & 2.20 \\
\hline
\end{tabular}


Table 6. Association a1 - a3 ADAM33 paternal and maternal haplotypes to histamine and methacholine bronchoprovocation tests

Table 6a. Association a1 - a3 ADAM33 paternal and maternal haplotypes to histamine bronchoprovocation tests.

\begin{tabular}{|c|c|c|c|c|}
\hline \multicolumn{2}{|c|}{ Paternal haplotypes } & \multicolumn{2}{|c|}{ Maternal haplotypes } & \multirow{2}{*}{$\begin{array}{c}\text { Comparison of maternal and } \\
\text { paternal haplotypes } \\
\text { in relative frequency } \\
\text { of II. group }{ }^{1}\end{array}$} \\
\hline Haplotypes & II. group & Haplotypes & II. group & \\
\hline a1 $(n=18)$ & $66.7 \%(12)^{a}$ & $\mathrm{a} 1(\mathrm{n}=21)$ & $61.9 \%(13)$ & $P=0.757$ \\
\hline $\mathrm{a} 2(\mathrm{n}=14)$ & $64.3 \%(9)^{a}$ & $\mathrm{a} 2(\mathrm{n}=18)$ & $66.7 \%(12)$ & $P=0.888$ \\
\hline a3 $(n=15)$ & $86.7 \%(13)^{b}$ & $\mathrm{a} 3(\mathrm{n}=8)$ & $75.0 \%(6)$ & $P=0.482$ \\
\hline other $(n=24)$ & $91.7 \%(22)^{b}$ & other $(n=24)$ & $83.3 \%(20)$ & $P=0.383$ \\
\hline $\begin{array}{l}\text { Differences in rela } \\
\text { among paterna }\end{array}$ & $\begin{array}{l}\text { uency of II. group } \\
\text { jpes: } P=0.013^{1}\end{array}$ & $\begin{array}{l}\text { Differences in rela } \\
\text { among materna }\end{array}$ & $\begin{array}{l}\text { dency of II. gr } \\
\text { pes: } P=0.412\end{array}$ & \\
\hline
\end{tabular}

Table 6b. Association a1 - a3 ADAM33 paternal and maternal haplotypes to methacholine bronchoprovocation tests.

\begin{tabular}{|c|c|c|c|c|}
\hline \multicolumn{2}{|c|}{ Paternal haplotypes } & \multicolumn{2}{|c|}{ Maternal haplotypes } & \multirow{2}{*}{$\begin{array}{l}\text { Comparison of maternal and } \\
\text { paternal haplotypes } \\
\text { in relative frequency } \\
\text { of II. group }{ }^{1}\end{array}$} \\
\hline Haplotypes & II. group & Haplotypes & II. group & \\
\hline $\mathrm{a} 1(\mathrm{n}=18)$ & $55.6 \%(10)$ & $\mathrm{a} 1(\mathrm{n}=21)$ & $57.1 \%(12)$ & $P=0.921$ \\
\hline $\mathrm{a} 2(\mathrm{n}=14)$ & $57.1 \%(8)$ & $\mathrm{a} 2(\mathrm{n}=18)$ & $55.6 \%(10)$ & $P=0.928$ \\
\hline $\mathrm{a} 3(\mathrm{n}=15)$ & $73.3 \%(11)$ & $\mathrm{a} 3(\mathrm{n}=8)$ & $37.5 \%(3)$ & $P=0.046$ \\
\hline other $(n=24)$ & $54.2 \%(13)$ & other $(n=24)$ & $66.7 \%(16)$ & $P=0.376$ \\
\hline
\end{tabular}

Differences in relative frequency of II. group Differences in relative frequency of II. group among paternal haplotypes: $P=0.658^{1} \quad$ among maternal haplotypes: $P=0.539^{1}$

a1, a2, a3 - haplotypes, group II. - medium - serious level of AHR - PC $20 \leq 2 \mathrm{mg} / \mathrm{ml}$ histamine and PC20 $\leq 16 \mathrm{mg} / \mathrm{ml} \mathrm{methacholine} \mathrm{was} \mathrm{performed}$ in $47(66 \%)$ asthmatic children, analysis of $\mathrm{N}=71$ patients

${ }^{1} P$ value of ML- $\chi^{2}$ test

${ }^{a-b}$ Marks of statistical significance - haplotypes marked by different letters are mutually significantly different in relative frequency of II. group

haplotype frequencies were due to the haplotype structure themselves. Three most common haplotypes showed a correlation with the severity of AHR (Tables 7, 8).

Airway hyperresponsiveness is a characteristic feature of asthma. Since its first description in 1946, the measurement of airway responsiveness with inhaled bronchoconstrictor stimuli, such as methacholine or histamine, has become a routine practice in the diagnosis and follow-up of asthma patients. The association between AHR and bronchial inflammation in asthma is supported by the observation that AHR increases with allergen exposure and is reduced by allergen avoidance and anti-inflammatory treatment. Histamine and methacholine act directly on the airway smooth muscle, while AMP-induced bronchoconstriction occurs predominantly indirectly by stimulation of adenosine A2B receptors on mast cells that facilitate their release of inflammatory mediators. Assessment of AHR provides information on the severity of the disease or effect of treatment used (at an interval) and, indirectly, on patient compliance ${ }^{21,22}$.
We tested whether 11 of the SNPs for ADAM33 could be associated with asthma or AHR in our patient sample. We compared the allele frequencies and frequencies of the most common haplotypes from our study with published data on Caucasian populations and found that the SNP frequencies were similar (data not shown). Some of the ADAM33 haplotypes had greater frequency differences to our study and two others (Tables 7 and 8 ) ( ref. $^{19,20}$ ). The haplotype analysis showed no association with asthma.

We found an association of severity of AHR predominantly with the a3 haplotype and differences in a3 haplotype distribution according to parental origin. The differences in frequencies in studies of all three haplotypes but mainly in the case of the a 3 haplotype, could be explained by the different way of haplotype construction rather than differences in the haplotype distribution between studies.

The correlation of haplotypes with AHR severity may reflect the role of ADAM33 in intercellular adhesion because of its disintegrin domain support $\alpha 9 \beta 1$ - 
Table 7. Frequencies of the most frequent ADAM 33 haplotypes in our and Australian ${ }^{19}$ studies. The haplotypes are built from SNPs common for the studies.

\begin{tabular}{ccccccccc}
\hline & \multicolumn{3}{c}{ SNPs name } & \multicolumn{3}{c}{ Frequency(\%) } \\
F+1 & S1 & S2 & ST+4 & T1 & T2 & V4 & German Caucasian & Czech Caucasian \\
\hline G & G & G & A & T & C & C & 31.59 & 17.57 \\
G & G & G & C & T & C & C & 16.53 & 14.41 \\
A & G & C & A & C & T & C & 14.00 & 10.81 \\
G & G & G & C & T & C & G & 11.22 & 5.86 \\
\hline
\end{tabular}

Table 8. Frequencies of the most frequent ADAM 33 haplotypes in our and German ${ }^{20}$ studies. The haplotypes are built from SNPs common for the studies.

\begin{tabular}{ccccccc}
\hline & & & & & \multicolumn{2}{c}{ Frequency(\%) } \\
F+1 & S1 & ST+4 & V4 & V5 & German Caucasian & Czech Caucasian \\
\hline G & G & A & C & A & 31.59 & 17.57 \\
G & G & C & C & A & 16.53 & 14.41 \\
A & G & A & C & A & 14.00 & 10.81 \\
G & G & C & G & A & 11.22 & 5.86 \\
\hline
\end{tabular}

integrin dependent leucocyte adhesion and the fact that mesenchymal cells, such as fibroblasts and smooth muscle cells, express this integrin ${ }^{23,24}$. The combinations of SNP genotypes in haplotypes could influence disintegrin domain function in intercellular adhesion, and therefore, influence the quantity of leukocytes and inflammatory reaction itself in airways. ADAM33 is a key molecule in the development and progression of asthma by influencing smooth muscle, vascular modeling and remodeling and, severity of AHR. Significant associations were found between the severity of AHR and phenotypes of asthmatics in our study.

\section{CONCLUSIONS}

The parental origin of asthma has been known for a long time. Reduced risk of asthma and AHR in children has been associated with the Val105 polymorphism of GSTP1 (glutathione S-transferase) in mothers of asthmatics ${ }^{25}$. The maternal influence is believed to have the greatest influence on atopy or asthma establishment. Surprisingly, we observed that three haplotypes (a1, a2, a3), predominantly the a3 haplotype, were associated with the severity of AHR and were significantly more often paternally transmitted. This different quantity of haplotype effects according to parental origin may be due to a distinct imprinting pattern of the alleles. Some genes are able to fully or partially escape epigenetic reprogramming during prenatal development and so they can preserve their special DNA methylation pattern ${ }^{26-28}$. Moreover, the specific epigenetic pattern can be transmitted to the descendant, and therefore, the epigenetic changes may be transmitted transgenerationally ${ }^{25,26}$. However, larger studies and meta-analyses are required to confirm the exact role of ADAM33 SNPs and the role of haplotype in the development of asthma.

\section{CONFLICT OF INTEREST STATEMENT}

Author's conflict of interest disclosure: None declared.

\section{REFERENCES}

1. Holgate ST, Arshad HS, Roberts GC, Howarth PH, Thurner P, Davies DE. A new look at the pathogenesis of asthma. 2009;118:439-50.

2. Shapiro SD, Owen CA. ADAM-33 surfaces as an asthma gene, NEJM 2002;347:936-38.

3. Van Eerdewegh P, Little RD, Dupuis J, Del Mastro RG, Falls K, Simon J, Torrey D, Pandit S, McKenny J, Braunschweiger K, Walsh A, Liu Z, Hayward B, Folz C, Manning SP, Bawa A, Saracino L, Thackston M, Benchekroun Y, Capparell N, Wang M, Adair R, Feng Y, Dubois J, FitzGerald MG, Huang H, Gibson R, Allen KM, Pedan A, Danzig MR, Umland SP, Egan RW, Cuss FM, Rorke S, Clough JB, Holloway JW, Holgate ST, Keith TP. Association of the ADAM33 gene with asthma and bronchial hyperresponsiveness. Nature 2002;418:426-30.

4. Howard TD, Postma D, Jongepier H, Moore WC, Koppelman GH, Zheng SL, Xu J, Bleecker ER, Meyers DA. Association of a disintegrin and metalloprotease 33 (ADAM33) gene with asthma in ethnically diverse populations. J. Allergy Clin Immunol 2003;112:717-22.

5. Lind DL, Choudhry S, Ung N, Ziv E, Avila PC, Salari K, Ha C, Lovins EG, Coyle NE, Nazario S, Casal J, Torres A, Rodriguez-Santana JR, Matallana H, Lilly CM, Salas J, Selman M, Boushey HA, Weiss ST, Chapela R, Ford JG, Rodriguez-Cintron W, Silverman EK, Sheppard D, Kwok PY, González Burchard El. ADAM33 is not associated with asthma in Puerto Rican or Mexican populations. Am J Respir Crit Care Med 2003;168:1312-6.

6. Zhang X, Su D, Zhang X, Sui H, Jin L, Lü F, Zhang J. Association of ADAM33 gene polymorphisms with adult concomitant allergic rhinitis and asthma in Chinese Han population. Molecular Biology Reports 2008;36:1505-9.

7. Wilkinson J, Grimley S, Collins A, Thomas NS, Holgate ST, Morton $\mathrm{N}$. Linkage of asthma to markers on chromosome 12 in a sample of 240 families using quantitative phenotype scores. Genomics 1998;53:251-9. 
8. Immervoll T, Loesgen S, Dütsch G, Gohlke H, Herbon N, Klugbauer S, Dempfle A, Bickeböller H, Becker-Follmann J, Rüschendorf F, Saar K, Reis A, Wichmann HE, Wjst M. Fine mapping and single nucleotide polymorphism association results of candidate genes for asthma and related phenotypes. Hum Mutat 2001;18:327-36.

9. Barnes KC, Freidhoff LR, Nickel R, Chiu YF, Juo SH, Hizawa N, Naidu RP, Ehrlich E, Duffy,D.L., Schou,C. Densemapping of chromosome 12q13.12-q23.3 and linkage to asthma and atopy. J Allergy Clin Immunol. 1999,104:485-91.

10. Koh YY, Park Y, Klim CK. The importance of maximal airway response to methacholine in the prediction of wheezing development in patients with cough-variant asthma. Allergy 2002;57:1165-70.

11. Murray AB, Ferguson AC, Morrison B. Airway responsiveness to his tamine as a test for overall severity of asthma in children. J Allergy Clin Immunol 1981;68:119-24.

12. Hargreave FE, Dolowich J, O’Byrne PM, Ramsdale EH, Daniel EE. The origin of airway hyperresponsiveness. J Allergy Clin Immunol 1986;78:825-32.

13. Barnes PJ, Adcock IM, Ito K. Histone acetylation and deacetylation: importance in inflammatory lung diseases. European Respiratory Journal 2005;25:552-63.

14. Zapletal A, Zemanek M, Paul T. Lung function in children and adolescents: methods and reference values. Progress in respiratory disease. Basel: Herzog. 1987.

15. Agresti A. Categorical data analysis.Ley-Interscience 2002;p.97.

16. Wentian Li. Three lectures on case-control genetic association analysis. Briefings in bioinformatics 2007;9:1-13.

17. Qin ZS, Niu T, Liu JS. Partition-Ligation-Expectation-Maximization Algorithm for Haplotype Inference with Single-Nucleotide Polymorphisms. Am J Hum Genet 2002,70:1242-7.

18. Stephens M, Donnelly P. A comparison of Bayesian methods for holotype reconstruction from population genotype data. Am J Hum Genet 2003;73:1162-9.
19. Kedda MA, Duffy DL, Bradley B, Beard R, Thompson PJ, Kedda MA. ADAM33 haplotypes are associated with asthma in a large Australian population. European Journal of Human Genetics 2006;14,1027-36.

20. Schedel M, Depner M, Schopen C, Weiland SK, Vogelberg C, Niggemann B, Lau S, Illig T, Klopp N, Wahn U, von Mutius E, Nickel $\mathrm{R}$, Kabesch $\mathrm{M}$. The role of polymorphisms in ADAM33, a disintegrin and metalloprotease 33, in childhood asthma and lung function in two German populations. Respiratory Research 2006;7:91.

21. Bisgaard $H$, Klug B. Lung function measurement in awake young children. Eur Respir J 1995;8:2067-75.

22. Evans TM, Rundell KW, Beck KC, Levine AM, Baumann JM. Airway narrowing measured by spirometry and impulse oscillometry following room temperature and cold temperature excercise. Chest 2005;128:2412-9.

23. Bridges LC, Sheppard D, Bowditch RD. ADAM disintegrin-like domain recognition by the lymphocyte integrins alpha4beta 1 and alpha4beta7. Biochem J 2005;387:101-8.

24. Wiester LM, Giachelli CM. Expression and function of the integrin alpha9beta1 in bovine aortic valve interstitial cells. J Heart Valve Dis 2003;12:605-16.

25. Child F, Lenney W, Clayton S, Davies S, Jones PW, Alldersea JE, Strange RC, Fryer AA. The association of maternal but not paternal genetic variation in GSTP1 with asthma phenotypes in children. Respir Med 2003;97:1247-56.

26. Martino DJ, Prescott SL. Silent mysteries: epigenetic paradigms could hold the key to conquering the epidemic of allergy and immune disease. Allergy 2010;65:7-15.

27. Dolinoy DC, Das R, Weidman JR, Jirtle RL. Metastable epialleles, imprinting, and the fetal origins of adult diseases. Pediatr Res 2007;61:30R-7R.

28. Rakyan VK, Chong S, Champ ME, Cuthbert PC, Morgan HD, Luu KV, Whitelaw E. Transgenerational inheritance of epigenetic states at the murine Axin(Fu) allele occurs after maternal and paternal transmission. Proc Natl Acad Sci 2003;100:2538-43. 